\title{
Synthesis and antiproliferative activities of polymethoxyflavones aminoalkyl and amino acid derivatives
}

https://doi.org/10.1515/hc-2020-0010

Received October 20, 2019; accepted February 04, 2020.

\begin{abstract}
Twelve novel aminoalkyl derivatives 3a-3f, 4a-4f and four novel amino acid derivatives $\mathbf{5 a}, \mathbf{5 b}, \mathbf{6} \mathbf{a}$ and $\mathbf{6 b}$ of polymethoxyflavones $\mathbf{1}$ and $\mathbf{2}$ were synthesized through regioselective demethylation, etherification, amination, EDCl-mediated amide condensation and alkaline hydrolysis, using tangeretin and nobiletin as starting materials. Their antiproliferative activities against four different human cancer cell lines (Aspc-1, SUN5, HepG-2 and HCT116) were evaluated by in vitro CCK- 8 assay. The results show that the majority of the synthetic compounds exhibited moderate to good antiproliferative activity. In particular, the antiproliferative activity of compound $\mathbf{5 b}$ against HepG-2 cells ( IC $\left._{50} 0.057 \mu \mathrm{M}\right)$ was equal to the positive control drug Staurosporine $\left(\mathrm{IC}_{50} 0.0575 \mu \mathrm{M}\right)$.
\end{abstract}

Keywords: polymethoxyflavones, aminoalkylated derivatives, amino acid derivatives, synthesis, antiproliferative activity.

\section{Introduction}

Polymethoxyflavonids (PMFs) are a class of natural products, which widely exist in Citrus plants possessing high anticancer activity [1-5], however, their bioavailability is low. The biological interest to develop structural analogs of anticancer agents possessing basic nitrogen atoms seemed highly desirable. It is reported that the introduction of an aminoalkyl side chain leads to a significant increase in biological activity and potency of the

\footnotetext{
*Corresponding author: Qiu-an Wang, College of Chemistry and Chemical Engineering, Hunan University, Changsha 410082, China, e-mail: WangQA@hnu.edu.cn

Li-qiong Ran, Xue-li Li and Man-hui Liu, College of Chemistry and Chemical Engineering, Hunan University, Changsha 410082, China
}

parent molecule [6-8]. The amino acid derivatives, such as tricin-amino acid derivatives, demonstrate favorable cell permeability and excellent bioavailability [9]. Quercetinamino acid derivatives are safe cancer multidrug resistance (MDR) modulators [10,11]. The results of these studies suggested that flavonoid conjugation with aminoalkyl groups or amino acids was the most promising approach to enhance its bioactivity and improve bioavailability.

As part of our screening program dedicated to the search for derivatives of natural flavonoids with anticancer properties[12-15], we herein synthesized two series of PMFs derivatives by attaching aminoakyl or amino acid moiety through a linking spacer to the free hydroxyl groups at the $\mathrm{C}-5$ position. Furthermore, their antiproliferative activities in vitro against four different human cancer cell lines including Aspc-1 (human pancreatic cancer), SUN-5 (human gastric cancer), HepG-2 (human hepatocellular carcinoma) and HCT-116 (human colon cancer) were evaluated by CCK-8 (cell counting kit-8) assay using Staurosporine as the positive control drug.

\section{Result and discussion}

The synthesis of novel PMF derivatives 3a-3f, 4a-4f, 5a, $\mathbf{5 b}, \mathbf{6 a}$ and $\mathbf{6 b}$ was performed according to the reaction pathways illustrated in Scheme 1. The inexpensive and easily accessible natural products tangeretin and nobiletin were used as the starting materials. Due to the neighboring-group participation of the C-4 carboxyl oxygen, tangeretin or nobiletin undergo regioselective demethylation of the C-5 methoxy group after treatment with a Lewis acids such as boron trichloride or aluminum chloride to give 5-demethyl tangeretin (1) or 5-demethyl nobiletin (2), respectively. We obtained compounds $\mathbf{1}$ and $\mathbf{2}$ with high yields of $93 \%$ and $90 \%$ respectively. PMFs 1 or $\mathbf{2}$ reacted with 1,2-diobromoethane in the presence of anhydrous $\mathrm{K}_{2} \mathrm{CO}_{3}$ in dry acetone to give compounds 7 or $\mathbf{8}$. The two latter reacted with various amines in the presence of $\mathrm{K}_{2} \mathrm{CO}_{3}$ 

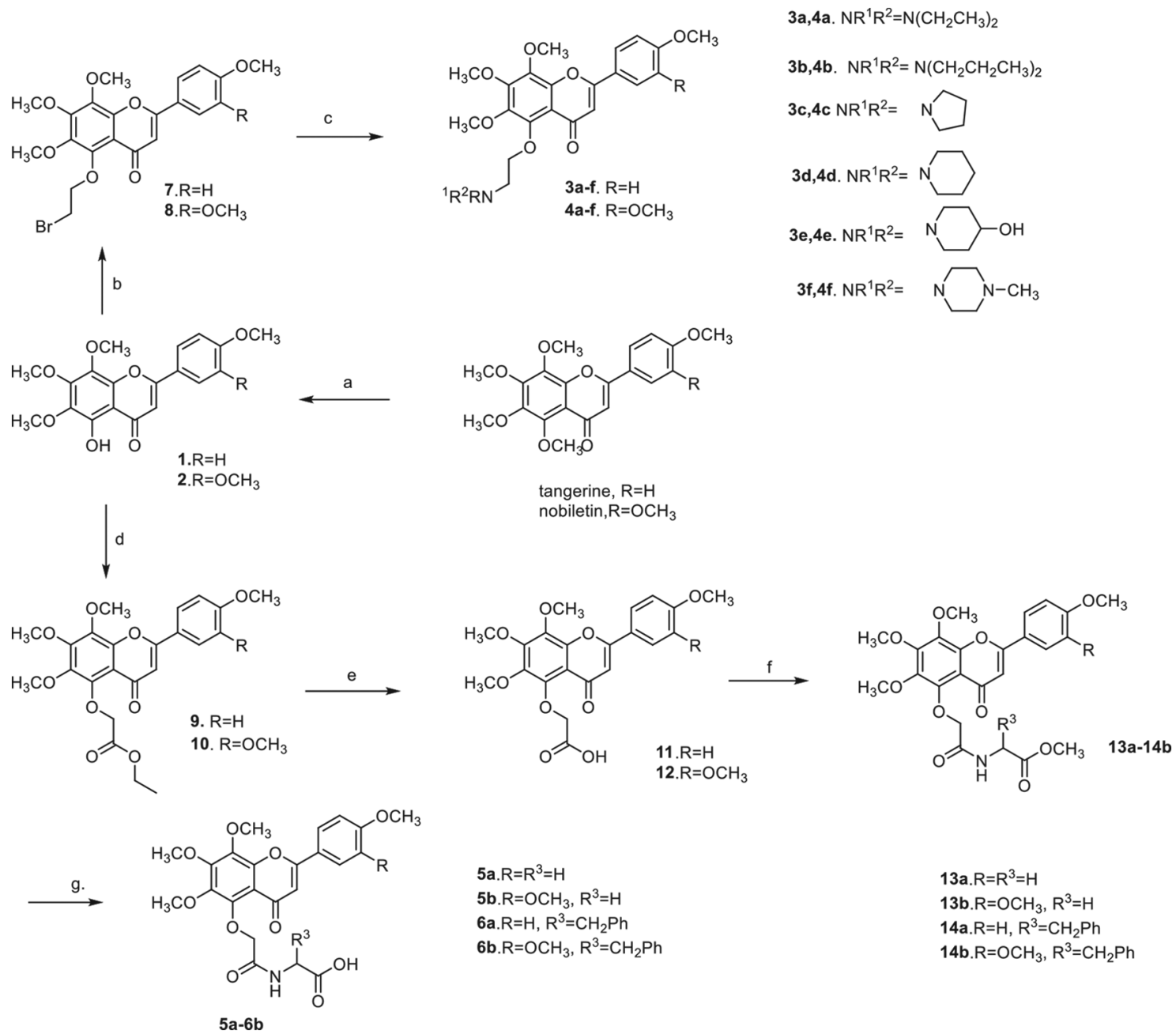

13a. $R=\mathrm{R}^{3}=\mathrm{H}$

13b. $\mathrm{R}=\mathrm{OCH}_{3}, \mathrm{R}^{3}=\mathrm{H}$

14a. $\mathrm{R}=\mathrm{H}, \mathrm{R}^{3}=\mathrm{CH}_{2} \mathrm{Ph}$

14b. $\mathrm{R}=\mathrm{OCH}_{3}, \mathrm{R}^{3}=\mathrm{CH}_{2} \mathrm{Ph}$

Scheme 1 Synthetic route of aminoalkyl and amino derivatives of polymethoxyflavones

Reagents and conditions: a. $\mathrm{AlCl}_{3}, \mathrm{CH}_{3} \mathrm{CO}_{2} \mathrm{C}_{2} \mathrm{H}_{5}$, reflux, then $5 \% \mathrm{HCl}(\mathrm{aq})$, reflux; b. $\mathrm{BrCH}_{2} \mathrm{CH}_{2} \mathrm{Br}, \mathrm{K}_{2} \mathrm{CO}_{3}$, DMF, heat; $\mathrm{C}$. $\mathrm{HNR}^{1} \mathrm{R}^{2}, \mathrm{~K}_{2} \mathrm{CO}_{3}, \mathrm{CH}_{3} \mathrm{CN}$, reflux; d. $\mathrm{ClCH}_{2} \mathrm{CO}_{2} \mathrm{C}_{2} \mathrm{H}_{5}, \mathrm{~K}_{2} \mathrm{CO}_{3}$, DMF, heat; e. $10 \% \mathrm{NaOH}$ (aq.), $\mathrm{CH}_{3} \mathrm{OH}$, r.t; f. $\mathrm{H}_{2} \mathrm{NCH}\left(\mathrm{R}^{3}\right) \mathrm{CO}_{2} \mathrm{CH}_{3}$, EDCl, DMAP, $\mathrm{CH}_{2} \mathrm{Cl}_{2}$, r.t; g. $10 \% \mathrm{NaOH}(\mathrm{aq})$, $\mathrm{CH}_{3} \mathrm{OH}$, r.t, then $1 \mathrm{M} \mathrm{HCl}(\mathrm{aq})$, r.t.

and KI, to give compounds 3a-3f and 4a-4f. These compounds are extending alkoxyl side chain at the 5-position, and introducing amine hydrogen bond receptor at the end of the side chain. Compounds $\mathbf{9}$ and $\mathbf{1 0}$ were usually prepared from etherification of the $5-\mathrm{OH}$ group by using methyl chloroacetate in the presence of a base. Two key intermediates 5-O-carboxyalkylated polymethoxy flavones 11 and 12 were synthesized by basic hydrolysis of 9 and 10 respectively.

Two amino acids, glycine (Gly) and phenylalanine (Phe) were attached to the 5-position of the PMFs ring via a non-hydrolysable linker. 5-O-carboxyalkylated PMFs $\mathbf{1 1}$ or $\mathbf{1 2}$ were condensed with glycine methyl ester hydrochloride or phenylalanine methyl ester hydrochloride, respectively, using 1-ethyl-3-(3-dimethylaminopropyl) carbodiimide hydrochloride (EDCl), $N$-hydroxybenzotriazole (HOBt) and 4-dimethylaminopyridine (DMAP) as efficient coupling reagents. The corresponding PMF glycine or phenlyamine derivatives $\mathbf{5 a}, \mathbf{5 b}, \mathbf{6} \mathbf{a}$ and $\mathbf{6 b}$ were obtained by hydrolysis of 13a, 13b, 14a and 14b. All the new compounds were purified by recrystallization or chromatography, and their structures were confirmed by means of ${ }^{1} \mathrm{HNMR},{ }^{13} \mathrm{CNMR}$, and MS spectra.

The antiproliferative activities of the synthesized polymethoxyflavones $\mathbf{1}$ and $\mathbf{2}$ and their aminoalkyl and amino acid derivatives 3a-3f, 4a-4f, 5a, 5b, 6a and $\mathbf{6 b}$ against four different human cancer cell lines (Aspc-1, SUN-5, HepG-2 and HCT-116) were evaluated by CCK-8 method. Based on this procedure, a dose-response curve was obtained for the four cell lines. Each test compound and the concentration that caused 50\% cell growth inhibition ( $\mathrm{IC}_{50}$, corresponding to the concentration of compound that inhibition $50 \%$ of net cell growth) was determined as described elsewhere.

As shown in Table 1, the majority of the synthetic compounds exhibited moderate to potent antiproliferative 
Table 1 Antiproliferative activities $\left[I C_{50}(\mu \mathrm{M})\right]^{\mathrm{a}}$ of synthetic compounds on four human cancer lines

\begin{tabular}{lcccc}
\hline Compound & Aspc-I & SNU5 & HepG2 & HCT116 \\
1 & $>50$ & $>50$ & $>50$ & $>50$ \\
2 & $>50$ & $>50$ & $>50$ & $>50$ \\
3a & $>50$ & $>50$ & $33.48 \pm 2.53$ & $26.58 \pm 7.67$ \\
3b & $23.01 \pm 3.61$ & $>50$ & $11.51 \pm 4.62$ & $12.68 \pm 2.59$ \\
3c & $49.71 \pm 2.10$ & $>50$ & $33.08 \pm 8.41$ & $29.89 \pm 5.11$ \\
3d & $45.60 \pm 3.20$ & $34.97 \pm 6.60$ & $26.36 \pm 5.34$ & $17.90 \pm 3.39$ \\
3e & $>50$ & $>50$ & $38.21 \pm 3.50$ & $>50$ \\
3f & $>50$ & $>50$ & $32.62 \pm 7.34$ & $31.04 \pm 1.56$ \\
4a & $>50$ & $>50$ & $>50$ & $39.03 \pm 2.72$ \\
4b & $43.24 \pm 5.62$ & $>50$ & $16.63 \pm 1.72$ & $18.24 \pm 5.86$ \\
4c & $>50$ & $>50$ & $>50$ & $>50$ \\
4d & $42.59 \pm 2.43$ & $>50$ & $>57 \pm 2.22$ & $34.62 \pm 6.05$ \\
4e & $>50$ & $>50$ & $>50$ & $>50$ \\
4f & $>50$ & $>50$ & $>50$ & $>50$ \\
5a & $>50$ & $>50$ & $>0.057 \pm 4.9 \mathrm{E}-05$ & $>50$ \\
5b & $>50$ & $>50$ & $>50$ & $>50$ \\
6a & $>50$ & $>50$ & $>50$ & $>50$ \\
6b & $>50$ & $>50$ & $0.0575 \pm 2.03 \mathrm{E}-05$ & $>50$ \\
Staurosporine & $0.0052 \pm 1.21 \mathrm{E}-06$ & $0.0208 \pm 2.5 \mathrm{E}-07$ & $0.02 \pm 1.0 \mathrm{E}-06$ \\
\hline
\end{tabular}

a Data are the mean \pm S.D. of three independent experiments performed.

activity. This shows that the introduction of aminoalkyl or amino acid moiety at 5-O-position of PMFs 1 or $\mathbf{2}$ produces the desired effect of increasing the antiproliferation activities. In particular, compound $\mathbf{5 b}$ clearly demonstrated the best results $\left(\mathrm{IC}_{50} 0.057 \mu \mathrm{M}\right)$ in the HepG-2 cell line studied. In fact, by comparing the structures $\mathbf{2}$ and $\mathbf{5 b}$, it can be concluded that the presence of phenylalanine amide moiety on 5-position of 5-demethyl nobiletin was associated with a remarkable increase in the growth inhibitory effect on HepG-2 cells. The benzyl function group between amido and carboxyl structure has more affinity to biological cells, so the biological activity is better than Gly derivative. It is suggested that the importance of this molecular modification is responsible for the activity when compared with the corresponding polymethoxy flavones. The clarification of the structural determinants for the potency would guide the design of novel potent drug molecules for future development.

\section{Conclusion}

Twelve novel aminoalkyl derivatives 3a-3f, 4a-4f and four novel amino acid derivatives $5 \mathbf{a}, 5 \mathbf{b}, \mathbf{6} \mathbf{a}$ and $\mathbf{6} \mathbf{b}$ of polymethoxyflavones were synthesized. Their antiproliferative activities in vitro results show that the majority of them exhibited moderate to good antiproliferative activity against four different human cancer cell lines (Aspc-1, SUN5, HepG-2 and HCT116). Among them, PMFs amino acid derivative $\mathbf{5 b}$ against HepG-2 cells $\left(\mathrm{IC}_{50} 0.057 \mu \mathrm{M}\right)$ was equal to the positive control drug Staurosporine $\left(\left(\mathrm{IC}_{50} 0.0575 \mu \mathrm{M}\right)\right.$ deserving further investigation.

\section{Experimental}

Melting points were determined via an XRC-1 apparatus and are uncorrected. ${ }^{1} \mathrm{HNMR}$ and ${ }^{13} \mathrm{CNMR}$ spectra were recorded on a Bruker-AV 400 spectrometer at 400 and $100 \mathrm{MHz}$, respectively, with TMS as an internal standard in $\mathrm{CDCl}_{3}$ or DMSO- $d_{6}$. Mass spectra (MS) and high-resolution mass spectra (HRMS) were determined on a VG Autospec-3000 or Mat 95 XP Spectrometer by the EI or ESI method. Column chromatography was carried out on silica gel 200-300 mesh (Qingdao Ocean Chemical Products of China). Commercially available AR or chemically pure reagents were used, and anhydrous solvents were dried and redistilled using standard experimental procedures.

5-Demethyl tangeretin (1) and 5-demethyl nobiletin (2) were prepared form tangeretin and noliletin according to previously published procedures [16].

General procedure for synthesis of bromoethanated polymethoxyflavones (7 and 8)

1,2-Dibromoethane (11.5 mmol) was added to a solution of PMFs 1 or $2(1.4 \mathrm{mmol})$ and $\mathrm{K}_{2} \mathrm{CO}_{3}(14.5 \mathrm{mmol})$ in acetone $(50 \mathrm{~mL})$, and the mixture was refluxed for $4 \mathrm{~h}$. The progress of the reaction was monitored by TLC. After cooling 
to room temperature, the mixture was filtered, the solvent was evaporated, and the residue was recrystallized from EtOH to yield compound 7 or 8 .

5-(2-Bromoethoxy)-4',6,7,8-tetramethoxyflavone (7) yellow solid; $76 \%$ yield; m.p. $122-124{ }^{\circ} \mathrm{C}$; ${ }^{1} \mathrm{H}$ NMR (400 $\left.\mathrm{MHz}, \mathrm{CDCl}_{3}\right): \delta 7.79$ (d, $J=8.3 \mathrm{~Hz}, 2 \mathrm{H}, 2^{\prime}-\mathrm{H}$ and $\left.6^{\prime}-\mathrm{H}\right), 6.94$ (d, $J=8.3 \mathrm{~Hz}, 2 \mathrm{H}, 3^{\prime}-\mathrm{H}$ and 5'-H), 6.49 (s, 1H, 3-H), 4.27 (t, $\left.J=6.5 \mathrm{~Hz}, 2 \mathrm{H}, 5-\mathrm{OCH}_{2}\right), 4.03,3.95,3.88,3.80$ (s/each, $12 \mathrm{H}$, $4 \mathrm{OCH}_{3}$ ), 3.70 (t, $\left.J=6.5 \mathrm{~Hz}, 2 \mathrm{H}, \mathrm{CH}_{2} \mathrm{Br}\right) .{ }^{13} \mathrm{C}$ NMR $(101 \mathrm{MHz}$, $\left.\mathrm{CDCl}_{3}\right): \delta 177.24,162.36,161.37,151.41,147.77,146.45,144.19$, 138.4, 127.74, 123.66, 114.80, 114.53, 106.56, 74.44, 62.12, 61.69, 55.52, 30.13 .

5-(2-Bromoethoxy)-3',4',6,7,8-pentamethoxyflavone (8) yellow solid; 79\% yield; m.p.116-118 ${ }^{\circ} \mathrm{C}$; ${ }^{1} \mathrm{H}$ NMR (400 MHz, $\left.\mathrm{CDCl}_{3}\right): \delta 7.50(\mathrm{~d}, J=8.4 \mathrm{~Hz}, 1 \mathrm{H}, 6$ '- $\mathrm{H}), 7.34(\mathrm{~s}, 1 \mathrm{H}$, 2'-H), $6.93\left(\mathrm{~d}, J=8.4 \mathrm{~Hz}, 1 \mathrm{H}, 5^{\prime}-\mathrm{H}\right), 6.53(\mathrm{~s}, 1 \mathrm{H}, 3-\mathrm{H}), 4.28$ (t, $J=6.5 \mathrm{~Hz}, 2 \mathrm{H}, 3-\mathrm{OCH}_{2}$ ), 4.04, 3.96, 3.90 (s/each, $15 \mathrm{H}$, $\left.5 \mathrm{OCH}_{3}\right), 3.71$ (t, $\left.J=6.5 \mathrm{~Hz}, 2 \mathrm{H}, \mathrm{CH}_{2} \mathrm{Br}\right) .{ }^{13} \mathrm{C}$ NMR $(101 \mathrm{MHz}$, $\left.\mathrm{CDCl}_{3}\right): \delta 177.27,161.26,152.02,151.48,149.31,147.77,146.52$, 144.23, 138.41, 123.89, 119.71, 114.79, 111.25, 108.57, 106.79, 74.47, 62.11, 61.73, 56.05, 30.08.

\section{General procedure for synthesis of aminalkyl-substitued polymethoxyflavone derivatives $3 a-3 f$ and $4 a-4 f$}

To a suspension of compounds 7 or $8(0.43 \mathrm{mmol})$ and $\mathrm{K}_{2} \mathrm{CO}_{3}(7.2 \mathrm{mmol})$ in acetonitrile $(20.0 \mathrm{~mL})$, the amine $(14.5 \mathrm{mmol})$ and a catalytic amount of KI $(0.07 \mathrm{mmol})$ were added. The resulting mixture was refluxed for 6-12h. After filtering, the resulting filtrate was evaporated to dryness under reduced pressure. The residue was suspended in water $(10.0 \mathrm{~mL})$ and extracted with dichloromethane $(3 \times 30 \mathrm{~mL})$. The combined organic layers were evaporated under reduced pressure, and the residue was recrystallized from EtOH to yield compounds 3a-3f or 4a-4f.

5-(2-Diethylaminoethoxy)-4',6,7,8-tetramethoxyflavone (3a) yellow solid; $80 \%$ yield; m.p. $110-112{ }^{\circ} \mathrm{C}$; ${ }^{1} \mathrm{H}$ NMR (400 MHz, $\left.\mathrm{CDCl}_{3}\right): \delta 7.79\left(\mathrm{~d}, J=7.8 \mathrm{~Hz}, 2 \mathrm{H}, 2^{\prime}-\mathrm{H}\right.$ and 6'-H), $6.95\left(\mathrm{~d}, J=7.8 \mathrm{~Hz}, 2 \mathrm{H}, 3^{\prime}-\mathrm{H}\right.$ and 5'-H), $6.50(\mathrm{~s}, 1 \mathrm{H}$, 3-H), 4.13 (t, $J=5.7 \mathrm{~Hz}, 2 \mathrm{H}, 5-\mathrm{OCH}_{2}$ ), 4.03, 3.95, 3.87, 3.81 (s/each, $\left.12 \mathrm{H}, 4 \mathrm{OCH}_{3}\right), 3.08\left(\mathrm{t}, J=5.7 \mathrm{~Hz}, 2 \mathrm{H}, \mathrm{CH}_{2}\right), 2.72$ (q, $\left.J=6.8 \mathrm{~Hz}, 4 \mathrm{H}, 2 \mathrm{NCH}_{2}\right), 1.06\left(\mathrm{t}, J=6.9 \mathrm{~Hz}, 6 \mathrm{H}, 2 \mathrm{CH}_{3}\right.$ ). ${ }^{13} \mathrm{C}$ NMR $\left(101 \mathrm{MHz}, \mathrm{CDCl}_{3}\right): \delta 177.49,162.37,161.43,151.52$, 147.74, 146.96, 144.13, 138.22, 127.74, 123.62, 114.6, 106.48, $71.89,61.98,61.65,55.52,52.20,47.67,11.29$. ESI- MS: $\mathrm{m} / \mathrm{z}$ $458[\mathrm{M}+\mathrm{H}]^{+}$. calc:458.21.

5-(2-Dipropylaminoethoxy)-4',6,7,8-tetramethoxyflavone (3b): yellow solid; 77\% yield; m.p. 88-90 ${ }^{\circ} \mathrm{C}$; ${ }^{1} \mathrm{H}$ NMR $\left(400 \mathrm{MHz}, \mathrm{CDCl}_{3}\right): \delta 7.77\left(\mathrm{~d}, J=8.1 \mathrm{~Hz}, 2 \mathrm{H}, 2^{\prime}-\mathrm{H}\right.$ and 6'-H), 6.91 (d, J= 8.2 Hz, 2H, 3'-H and 5'-H), 6.48 (s, 1H,
3-H), $4.06\left(\mathrm{t}, J=6.7 \mathrm{~Hz}, 2 \mathrm{H}, 5-\mathrm{OCH}_{2}\right), 4.00,3.93,3.85,3.77$ (s/each, $\left.12 \mathrm{H}, 4 \mathrm{OCH}_{3}\right), 2.95\left(\mathrm{t}, J=6.7 \mathrm{~Hz}, 2 \mathrm{H}, \mathrm{CH}_{2}\right), 2.42-2.27$ $\left(\mathrm{m}, 4 \mathrm{H}, 2 \mathrm{NCH}_{2}\right), 1.46-1.36\left(\mathrm{~m}, 4 \mathrm{H}, 2 \mathrm{CH}_{2}\right), 0.78(\mathrm{t}, J=7.2 \mathrm{~Hz}$, $\left.6 \mathrm{H}, 2 \mathrm{CH}_{3}\right) .{ }^{13} \mathrm{C}$ NMR $\left(101 \mathrm{MHz}, \mathrm{CDCl}_{3}\right): \delta 177.21,162.21,161.02$, $151.29,147.58,144.05,137.90,127.61,123.72,114.93,114.44$, 106.52, 73.20, 61.89, 61.58, 56.77, 55.44, 53.71, 20.41, 11.89. ESI-MS: $\mathrm{m} / \mathrm{z}$ 486[M+H] $]^{+}$. calc:486.24.

5-(2-Pyrrolidinylethoxy)-4',6,7,8-tetramethoxyflavone (3c) yellow solid; $87 \%$ yield; m.p. $98-100{ }^{\circ} \mathrm{C}$; ${ }^{1} \mathrm{H}$ NMR (400 MHz, $\left.\mathrm{CDCl}_{3}\right): \delta 7.87\left(\mathrm{~d}, J=8.0 \mathrm{~Hz}, 2 \mathrm{H}, 2^{\prime}-\mathrm{H}\right.$ and 6'-H), $7.02\left(\mathrm{~d}, J=8.1 \mathrm{~Hz}, 2 \mathrm{H}, 3^{\prime}-\mathrm{H}\right.$ and 5'-H), 6.57 (s, $1 \mathrm{H}, 3-\mathrm{H}), 4.20\left(\mathrm{t}, J=6.0 \mathrm{~Hz}, 2 \mathrm{H}, 5-\mathrm{OCH}_{2}\right), 4.10,4.03,3.95$, 3.89 (s/each, $12 \mathrm{H}, 4 \mathrm{OCH}_{3}$ ), $3.07\left(\mathrm{t}, J=6.0 \mathrm{~Hz}, 2 \mathrm{H}, \mathrm{CH}_{2}\right.$ ), 2.72$2.63\left(\mathrm{~m}, 4 \mathrm{H}, 2 \mathrm{NCH}_{2}\right), 1.83-1.75\left(\mathrm{~m}, 4 \mathrm{H}, 2 \mathrm{CH}_{2}\right) .{ }^{13} \mathrm{C}$ NMR $(101$ $\left.\mathrm{MHz}, \mathrm{CDCl}_{3}\right): \delta 177.25,162.26,161.12,151.35,147.70,147.37$, 144.17, 138.06, 127.68, 123.79, 114.99, 114.49, 106.58, 73.43, 61.94, 61.61, 55.55, 54.38, 23.55. ESI-MS: m/z $478[\mathrm{M}+\mathrm{Na}]^{+}$. calc:478.19.

5-(2-Piperidinylethoxy)-4',6,7,8-tetramethoxyflavone (3d) yellow solid; $86 \%$ yield; m.p. $106-108{ }^{\circ} \mathrm{C}$; ${ }^{1} \mathrm{H}$ NMR (400 MHz, $\left.\mathrm{CDCl}_{3}\right): \delta 7.78\left(\mathrm{~d}, J=8.0 \mathrm{~Hz}, 2 \mathrm{H}, 2^{\prime}-\mathrm{H}\right.$ and 6'-H), $6.93\left(\mathrm{~d}, J=8.0 \mathrm{~Hz}, 2 \mathrm{H}, 3^{\prime}-\mathrm{H}\right.$ and 5'-H), 6.49 (s, 1H, $3-\mathrm{H}), 4.10\left(\mathrm{t}, J=6.0 \mathrm{~Hz}, 2 \mathrm{H}, 5-\mathrm{OCH}_{2}\right), 4.01,3.94,3.86,3.79$ (s/each, $12 \mathrm{H}, 4 \mathrm{OCH}_{3}$ ), $2.82\left(\mathrm{t}, J=5.9 \mathrm{~Hz}, 2 \mathrm{H}, \mathrm{CH}_{2}\right), 2.47-2.41$ (m, 4H, $\left.2 \mathrm{NCH}_{2}\right), 1.59-1.46\left(\mathrm{~m}, 4 \mathrm{H}, 2 \mathrm{CH}_{2}\right), 1.36-1.29(\mathrm{~m}, 2 \mathrm{H}$, $\left.\mathrm{CH}_{2}\right) \cdot{ }^{13} \mathrm{C}$ NMR $\left(101 \mathrm{MHz}, \mathrm{CDCl}_{3}\right): \delta 177.12,162.20,161.05$, 151.24, 147.66, 147.27, 144.04, 138.04, 127.59, 123.63, 114.99, $114.42,106.45,71.60,66.95,61.97,61.84,61.56,58.45,55.41$, 53.78. ESI-MS: $\mathrm{m} / \mathrm{z} 508[\mathrm{M}+\mathrm{K}]^{+}$. calc:508.21.

5-(2-(4-Hydroxypiperidinyl)ethoxy)-4',6,7,8-tetramethoxyflavone (3e) yellow solid; $77 \%$ yield; m.p. $108-110{ }^{\circ} \mathrm{C}$; ${ }^{1} \mathrm{H} \mathrm{NMR}\left(400 \mathrm{MHz}, \mathrm{CDCl}_{3}\right): \delta 7.77(\mathrm{~d}, J=7.7 \mathrm{~Hz}$, $2 \mathrm{H}, 2^{\prime}-\mathrm{H}$ and 6'-H), $6.92\left(\mathrm{~d}, J=7.8 \mathrm{~Hz}, 2 \mathrm{H}, 3^{\prime}-\mathrm{H}\right.$ and 5'-H), 6.48 (s, $1 \mathrm{H}, 3-\mathrm{H}), 4.09$ (t, $\left.J=5.2 \mathrm{~Hz}, 2 \mathrm{H}, 5-\mathrm{OCH}_{2}\right), 4.01,3.93$, $3.85,3.78\left(\mathrm{~s} / \mathrm{each}, 12 \mathrm{H}, 4 \mathrm{OCH}_{3}\right), 3.65-3.78(\mathrm{~m}, 1 \mathrm{H}, \mathrm{CH}), 2.96-$ $2.84\left(\mathrm{~m}, 4 \mathrm{H}, 2 \mathrm{NCH}_{2}\right), 2.27\left(\mathrm{t}, J=5.2 \mathrm{~Hz}, 2 \mathrm{H}, \mathrm{NCH}_{2}\right), 1.85-1.76$ $\left(\mathrm{m}, 2 \mathrm{H}, \mathrm{CH}_{2}\right), 1.62-1.53\left(\mathrm{~m}, 2 \mathrm{H}, \mathrm{CH}_{2}\right) .{ }^{13} \mathrm{C}$ NMR $(101 \mathrm{MHz}$, $\left.\mathrm{CDCl}_{3}\right): \delta 177.36,162.25,161.22,151.35,147.69,147.24,144.07$, 138.01, 127.68, 123.60, 114.84, 114.45, 106.43, 72.12, 67.43, 61.96, 61.62, 57.71, 55.47, 51.31, 34.29, 31.53, 22.61, 14.11. ESI-MS: $\mathrm{m} / \mathrm{z} 508[\mathrm{M}+\mathrm{Na}]^{+}$. calc:508.20.

5-(2-(1-Methylhexahydropyrazinyl)ethoxy)4',6,7,8-tetramethoxyflavone (3f) yellow solid; $86 \%$ yield; m.p. $104-106{ }^{\circ} \mathrm{C}$; ${ }^{1} \mathrm{H}$ NMR $\left(400 \mathrm{MHz}, \mathrm{CDCl}_{3}\right): \delta 7.78$ (d, $J=8.5 \mathrm{~Hz}, 2 \mathrm{H}, 2^{\prime}-\mathrm{H}$ and $\left.6^{\prime}-\mathrm{H}\right), 6.93(\mathrm{~d}, J=8.5 \mathrm{~Hz}, 2 \mathrm{H}$, 3'- $-\mathrm{H}$ and 5'-H), 6.49 (s, 1H, 3-H), 4.09 (t, $J=5.7 \mathrm{~Hz}, 2 \mathrm{H}$, $\left.5-\mathrm{OCH}_{2}\right), 4.01,3.94,3.86,3.79$ (s/each, $\left.12 \mathrm{H}, 4 \mathrm{OCH}_{3}\right), 2.84$ (t, $\left.J=5.7 \mathrm{~Hz}, 2 \mathrm{H}, \mathrm{CH}_{2}\right), 2.58-2.52\left(\mathrm{~m}, 4 \mathrm{H}, 2 \mathrm{NCH}_{2}\right), 2.41-2.32$ $\left(\mathrm{m}, 4 \mathrm{H}, 2 \mathrm{CH}_{2}\right), 2.20\left(\mathrm{~s}, 3 \mathrm{H}, \mathrm{CH}_{3}\right) .{ }^{13} \mathrm{C} \mathrm{NMR}\left(101 \mathrm{MHz}, \mathrm{CDCl}_{3}\right)$ : $\delta$ 176.1, 161.22, 160.06, 150.27, 146.69, 146.40, 143.10, 137.02, 126.64, 122.76, 114.04, 113.46, 105.55, 71.08, 60.95, 60.61, 
56.92, 54.46, 54.13, 52.32, 45.07. ESI-MS: m/z $507[\mathrm{M}+\mathrm{Na}]^{+}$. calc:507.22.

5-(2-Diethylaminoethoxy)-3',4',6,7,8-pentamethoxyflavone(4a) yellow solid; 78\% yield; m.p. 142-144 ${ }^{\circ} \mathrm{C}$; ${ }^{1} \mathrm{H}$ NMR $\left(400 \mathrm{MHz}, \mathrm{CDCl}_{3}\right): \delta 7.48(\mathrm{~d}, J=8.3 \mathrm{~Hz}, 1 \mathrm{H}$, 6'-H), 7.33 (s, 1H, 2'-H), 6.91 (d, $\left.J=8.3 \mathrm{~Hz}, 1 \mathrm{H}, 5^{\prime}-\mathrm{H}\right), 6.51$ (s, $1 \mathrm{H}, 3-\mathrm{H}), 4.06\left(\mathrm{t}, J=6.3 \mathrm{~Hz}, 2 \mathrm{H}, 5-\mathrm{OCH}_{2}\right), 4.02,3.95$, 3.91-3.86 (s/each, $\left.15 \mathrm{H}, 5 \mathrm{OCH}_{3}\right), 2.98\left(\mathrm{t}, J=6.3 \mathrm{~Hz}, 2 \mathrm{H}, \mathrm{CH}_{2}\right.$ ), $2.62\left(\mathrm{q}, J=6.7 \mathrm{~Hz}, 4 \mathrm{H}, 2 \mathrm{NCH}_{2}\right), 1.01\left(\mathrm{t}, J=6.9 \mathrm{~Hz}, 6 \mathrm{H}, 2 \mathrm{CH}_{3}\right)$. ${ }^{13} \mathrm{C}$ NMR $\left(101 \mathrm{MHz}, \mathrm{CDCl}_{3}\right): \delta 177.28,160.97,151.86,151.40$, $149.20,147.68$, 147.42, 144.09, 137.91, 123.90, 119.58, 114.89, 111.18, 108.44, 106.71, 72.87, 61.90, 61.63, 55.98, 52.37, 47.49, 11.75. ESI-MS: m/z $488[\mathrm{M}+\mathrm{H}]^{+}$. calc:488.22.

5-(2-(Dipropylaminoethoxy)-3',4',6,7,8-pentamethoxyflavone (4b) yellow solid; 75\% yield; m.p. 160-162 ${ }^{\circ} \mathrm{C}$; ${ }^{1} \mathrm{H}$ NMR $\left(400 \mathrm{MHz}, \mathrm{CDCl}_{3}\right): \delta 7.46(\mathrm{~d}, J=8.2 \mathrm{~Hz}, 1 \mathrm{H}$, 6'-H), 7.31 (s, 1H, 2'-H), 6.90 (d, $\left.J=8.2 \mathrm{~Hz}, 1 \mathrm{H}, 5^{\prime}-\mathrm{H}\right), 6.50$ (s, $1 \mathrm{H}, 3-\mathrm{H}), 4.02\left(\mathrm{t}, J=6.1 \mathrm{~Hz}, 2 \mathrm{H}, 5-\mathrm{OCH}_{2}\right), 4.02,3.94,3.86$ (s/each, 15H, $5 \mathrm{OCH}_{3}$ ), $2.94\left(\mathrm{t}, J=6.1 \mathrm{~Hz}, 2 \mathrm{H}, \mathrm{CH}_{2}\right), 2.41-2.32$ $\left(\mathrm{m}, 4 \mathrm{H}, 2 \mathrm{NCH}_{2}\right), 1.40-1.34\left(\mathrm{~m}, 4 \mathrm{H}, 2 \mathrm{CH}_{2}\right), 0.78(\mathrm{t}, J=6.9$ $\left.\mathrm{Hz}, 6 \mathrm{H}, 2 \mathrm{CH}_{3}\right) .{ }^{13} \mathrm{C} \mathrm{NMR}\left(101 \mathrm{MHz}, \mathrm{CDCl}_{3}\right): \delta 177.16,160.82$, 151.78, 151.31, 149.15, 147.64, 147.54, 144.04, 137.79, 123.90, 119.51, 114.90, 111.13, 108.36, 106.70, 73.22, 61.89, 61.80, 61.59, 56.74, 56.00, 55.84, 53.64, 20.39, 11.89. ESI-MS: m/z $516[\mathrm{M}+\mathrm{H}]^{+}$. calc: 516.25 .

5-(2-(Pyrrolidinylethoxy)-3',4',6,7,8-pentamethoxyflavone (4c) yellow solid; 89\% yield; m.p. 124-126 ${ }^{\circ} \mathrm{C}$; ${ }^{1} \mathrm{H}$ NMR $\left(400 \mathrm{MHz}, \mathrm{CDCl}_{3}\right): \delta 7.47(\mathrm{~d}, J=8.3 \mathrm{~Hz}, 1 \mathrm{H}$, 6'-H), 7.32 (s, 1H, 2'-H), 6.91 (d, $\left.J=8.4 \mathrm{~Hz}, 1 \mathrm{H}, 5^{\prime}-\mathrm{H}\right), 6.50$ (s, 1H, 3-H), $4.13\left(\mathrm{t}, J=5.4 \mathrm{~Hz}, 2 \mathrm{H}, 5-\mathrm{OCH}_{2}\right), 4.02,3.95,3.88$ (s/each, $15 \mathrm{H}, 5 \mathrm{OCH}_{3}$ ), $3.01\left(\mathrm{t}, J=5.4 \mathrm{~Hz}, 2 \mathrm{H}, \mathrm{CH}_{2}\right), 2.67-2.59$ (m, 4H, 2NCH $)$ ) $1.76-1.71\left(\mathrm{~m}, 4 \mathrm{H}, 2 \mathrm{CH}_{2}\right) .{ }^{13} \mathrm{C}$ NMR (101 MHz, $\mathrm{CDCl}_{3}$ ): $\delta 177.24,160.97,151.87,151.39,149.21,147.33,144.15$, 137.97, 123.91, 119.58, 114.89, 111.19, 108.47, 106.71, 78.98, 73.30, 67.76 , 64.67, 54.35, 23.51. ESI-MS: m/z 508 [M+Na]+. calc:508.20.

5-(2-(Piperidinylethoxy)-3',4',6,7,8-pentamethoxyflavone (4d) yellow solid; $88 \%$ yield; m.p. 148-150 ${ }^{\circ} \mathrm{C} ;{ }^{1} \mathrm{H}$ NMR (400 MHz, $\mathrm{CDCl}_{3}$ ): 87.49 (d, $J=7.3 \mathrm{~Hz}, 1 \mathrm{H}, 6$ '-H), 7.33 (s, 1H, 2'-H), 6.92 (d, J = 8.1 Hz, 1H, 5'-H), 6.51 (s, 1H, 3-H), $4.15\left(\mathrm{t}, J=5.1 \mathrm{~Hz}, 2 \mathrm{H}, 5-\mathrm{OCH}_{2}\right), 4.02,3.95,3.91,3.86(\mathrm{~s} /$ each, $\left.15 \mathrm{H}, 5 \mathrm{OCH}_{3}\right), 2.95\left(\mathrm{t}, J=5.1 \mathrm{~Hz}, 2 \mathrm{H}, \mathrm{CH}_{2}\right), 2.64-2.58(\mathrm{~m}$, $\left.4 \mathrm{H}, 2 \mathrm{NCH}_{2}\right), 1.60-1.53\left(\mathrm{~m}, 4 \mathrm{H}, 2 \mathrm{CH}_{2}\right), 1.42-1.38\left(\mathrm{~m}, 2 \mathrm{H}, \mathrm{CH}_{2}\right)$. ${ }^{13} \mathrm{C}$ NMR $\left(101 \mathrm{MHz}, \mathrm{CDCl}_{3}\right): \delta 177.37,161.13,151.93,151.47$, 149.23, 147.70, 147.19, 144.11, 138.04, 123.86, 119.65, 114.81, $111.20,108.48,106.71,71.75,61.94,61.65,58.36,56.01,54.56$, 25.47, 23.89. ESI-MS: $\mathrm{m} / \mathrm{z} 500[\mathrm{M}+\mathrm{H}]^{+}$. calc:500.22.

5-(2-(4-Hydroxypiperidinyl) ethoxy)-3',4',6,7,8-pentamethoxyflavone (4e) yellow solid; 74\% yield; m.p. 195-197 ${ }^{\circ} \mathrm{C}$; ${ }^{1} \mathrm{H} \mathrm{NMR}\left(400 \mathrm{MHz}, \mathrm{CDCl}_{3}\right): \delta 7.47(\mathrm{~d}, J=8.2 \mathrm{~Hz}$, 1H, 6'-H), 7.32 (s, 1H, 2'-H), 6.90 (d, $\left.J=8.4 \mathrm{~Hz}, 1 \mathrm{H}, 5^{\prime}-\mathrm{H}\right)$, $6.50(\mathrm{~s}, 1 \mathrm{H}, 3-\mathrm{H}), 4.09\left(\mathrm{t}, J=5.3 \mathrm{~Hz}, 2 \mathrm{H}, 5-\mathrm{OCH}_{2}\right), 4.02,3.94$, 3.87 (s/each, $\left.15 \mathrm{H}, 5 \mathrm{OCH}_{3}\right), 3.65-3.61(\mathrm{~m}, 1 \mathrm{H}, \mathrm{CH}), 2.90-2.83$ (m, 4H, $\left.2 \mathrm{NCH}_{2}\right), 2.27\left(\mathrm{t}, J=5.3 \mathrm{~Hz}, 2 \mathrm{H}, \mathrm{NCH}_{2}\right), 1.85-1.76(\mathrm{~m}$, $\left.2 \mathrm{H}, \mathrm{CH}_{2}\right), 1.57-1.51\left(\mathrm{~m}, 2 \mathrm{H}, \mathrm{CH}_{2}\right) .{ }^{13} \mathrm{C}$ NMR $\left(101 \mathrm{MHz}, \mathrm{CDCl}_{3}\right)$ : $\delta 177.31,161.07,151.89,151.40,149.20,147.67,147.29,144.10$, 137.95, 123.84, 119.63, 114.84, 111.20, 108.48, 106.65, 72.14, 67.38, 61.91, 61.62, 57.73, 55.98, 51.28, 34.30. ESI-MS: m/z $516[\mathrm{M}+\mathrm{H}]^{+}$. calc:516.22.

5-(2-(1-Methylhexahydropyrazinyl)ethoxy)3',4',6,7,8-pentamethoxyflavone (4f) yellow solid; $85 \%$ yield; m.p. $138-140{ }^{\circ} \mathrm{C}$; ${ }^{1} \mathrm{H}$ NMR $\left(400 \mathrm{MHz}, \mathrm{CDCl}_{3}\right): \delta 7.48$ (d, $\left.J=8.4 \mathrm{~Hz}, 1 \mathrm{H}, 6{ }^{\prime}-\mathrm{H}\right), 7.32\left(\mathrm{~s}, 1 \mathrm{H}, 2^{\prime}-\mathrm{H}\right), 6.91$ (d, $J=8.4 \mathrm{~Hz}, 1 \mathrm{H}$, 5'-H), 6.50 (s, $1 \mathrm{H}, 3-\mathrm{H}), 4.09$ (t, $J=5.3 \mathrm{~Hz}, 2 \mathrm{H}, 5-\mathrm{OCH}_{2}$ ), 4.02, 3.95, 3.88 (s/each, $15 \mathrm{H}, 5 \mathrm{OCH}_{3}$ ), $2.83\left(\mathrm{t}, J=5.3 \mathrm{~Hz}, 2 \mathrm{H}, \mathrm{CH}_{2}\right.$ ), 2.57-2.49 (m, 4H, $\left.2 \mathrm{NCH}_{2}\right), 2.41-2.34\left(\mathrm{~m}, 4 \mathrm{H}, 2 \mathrm{CH}_{2}\right), 2.20(\mathrm{~s}$, $\left.3 \mathrm{H}, \mathrm{CH}_{3}\right) .{ }^{13} \mathrm{C} \mathrm{NMR}\left(101 \mathrm{MHz}, \mathrm{CDCl}_{3}\right): \delta 177.16,160.90,151.84$, 151.31, 149.20, 147.66, 147.42, 144.11, 137.93, 123.93, 119.55, 115.00, 111.17, 108.44, 106.73, 72.04, 61.91, 61.62, 57.92, 55.96, 55.12, 53.32, 46.07. ESI-MS: m/z 537 [M+Na] ${ }^{+}$. calc: 537.23.

\section{General procedure for synthesis of carboxylic acid derivatives of polymethoxyflavonoids 11 and 12}

A mixture of 1 or $\mathbf{2}(1.3 \mathrm{mmol})$ and potassium carbonate $(1.6 \mathrm{mmol})$ were dissolved in $40 \mathrm{ml} \mathrm{DMF}$ and added into a $100 \mathrm{ml}$ three-necked round-bottomed flask. The reaction mixture was heated to $40^{\circ} \mathrm{C}$, then ethyl chloroacetate $(9.07$ $\mathrm{mmol}$ ) was added dropwise into the mixture. The reaction mixture was stirred for $6 \mathrm{~h}$ at $40^{\circ} \mathrm{C}$ and then cooled to room temperature. A total of $500 \mathrm{ml}$ of cold water was added to the mixture. The solid that separated was filtered, washed with water and dried to obtain $0.48 \mathrm{~g}$ of compound 9 or 10.

A mixture of $\mathbf{9}$ or $\mathbf{1 0}(1.13 \mathrm{mmol})$ was dissolved in 40 $\mathrm{ml}$ methanol and added into a $100 \mathrm{ml}$ three-necked roundbottomed flask equipped and stirred at room temperature. $10 \mathrm{~mL}$ of $10 \% \mathrm{NaOH}$ aqueous solution was added dropwise into the mixture. The reaction mixture was stirred for $2 \mathrm{~h}$ at room temperature and then was concentrated under reduced pressure to obtain a white liquid. The $\mathrm{pH}$ of the mixture was adjusted to be between 2 and 3 using $6 \mathrm{~mol} / \mathrm{L}$ hydrochloric acid, The mixture was extracted with dichloromethane, the organic layer was dried over anhydrous magnesium sulfate, and concentrated under reduced pressure to obtain white powder, which was recrystallized with ethanol and filtered to obtain $0.38 \mathrm{~g}$ compound $\mathbf{1 1}$ or $\mathbf{1 2}$.

5-(0-Ethoxyacetyl)-4',6,7,8-tetramethoxyflavone (9) yellow solid; $80 \%$ yield; m.p. $110-112{ }^{\circ} \mathrm{C}$; ${ }^{1} \mathrm{H}$ NMR (400 $\left.\mathrm{MHz}, \mathrm{CDCl}_{3}\right): \delta 7.78\left(\mathrm{~d}, J=8.0 \mathrm{~Hz}, 2 \mathrm{H}, 2^{\prime}-\mathrm{H}\right.$ and $\left.6^{\prime}-\mathrm{H}\right), 6.94$ (d, $J=8.0 \mathrm{~Hz}, 2 \mathrm{H}, 3^{\prime}-\mathrm{H}^{\prime}$ and 5'-H), $6.50(\mathrm{~s}, 1 \mathrm{H}, 3-\mathrm{H}), 4.61$ (s, $\left.2 \mathrm{H}, 3-\mathrm{OCH}_{2}\right), 4.22\left(\mathrm{q}, J=6.9 \mathrm{~Hz}, 2 \mathrm{H}, \mathrm{CH}_{2}\right), 4.02,3.95,3.89$, 
$3.80(4 \mathrm{~s}, 12 \mathrm{H}, 4 \mathrm{OCH}), 1.25\left(\mathrm{t}, J=7.0 \mathrm{~Hz}, 3 \mathrm{H}, \mathrm{CH}_{3}\right) ;{ }^{13} \mathrm{C} \mathrm{NMR}$ $\left(101 \mathrm{MHz}, \mathrm{CDCl}_{3}\right): \delta 175.99,168.00,161.29,160.27,150.28$, $146.58,145.02,142.87,137.51,126.68,122.63,113.71,113.48$, 105.53, 70.08, 61.11, 61.03, 60.63, 59.95, 54.47, 13.21.

5-(0-Ethoxyacetyl)-3',4',6,7,8-pentamethoxyflavone (10) yellow solid; 78\% yield; m.p.112-114 ${ }^{\circ} \mathrm{C} ;{ }^{1} \mathrm{H}$ NMR $\left(400 \mathrm{MHz}, \mathrm{CDCl}_{3}\right): \delta 7.47\left(\mathrm{~d}, J=8.4 \mathrm{~Hz}, 1 \mathrm{H}, 6^{\prime}-\mathrm{H}\right), 7.31(\mathrm{~s}, 1 \mathrm{H}$, 2'-H), 6.91 (d, J = 8.4 Hz, 1H, 5'-H), 6.51 (s, 1H, 3-H), 4.61 (s, $2 \mathrm{H}, 5-\mathrm{OCH}_{2}$ ), $4.22\left(\mathrm{q}, J=6.9 \mathrm{~Hz}, 2 \mathrm{H}, \mathrm{CH}_{2}\right), 4.02,3.95(2 \mathrm{~s}, 6 \mathrm{H}$, $\left.2 \mathrm{OCH}_{3}\right), 3.89\left(\mathrm{~s}, 6 \mathrm{H}, 2 \mathrm{OCH}_{3}\right), 3.87\left(\mathrm{~s}, \mathrm{H}, \mathrm{OCH}_{3}\right), 1.24$ (t, $J=$ $\left.7.0 \mathrm{~Hz}, 3 \mathrm{H}, \mathrm{CH}_{3}\right) ;{ }^{13} \mathrm{C} \mathrm{NMR}\left(101 \mathrm{MHz}, \mathrm{CDCl}_{3}\right): \delta 175.95,167.97$, 160.11, 150.93, 150.33, 148.23, 146.56, 145.07, 142.88, 137.44, 122.83, 118.62, 113.69, 110.21, 107.49, 105.72, 70.09, 61.10, 60.95, 60.64, 59.95, 55.06, 54.92, 13.21.

5-(0-Carboxymethyl)-4',6,7,8-tetramethoxyflavone (11) yellow solid; $76 \%$ yield; m.p.138-140 ${ }^{\circ} \mathrm{C}$; ${ }^{1} \mathrm{H}$ NMR (400 MHz, $\mathrm{CDCl}_{3}$ ): $\delta 13.93(\mathrm{~s}, 1 \mathrm{H}, \mathrm{COOH}), 7.83(\mathrm{~d}, J=8.1$ $\mathrm{Hz}, 2 \mathrm{H}, 2^{\prime}-\mathrm{H}$ and 6'-H), 6.98 (d, $J=8.2 \mathrm{~Hz}, 2 \mathrm{H}, 3^{\prime}-\mathrm{H}$ and 5'-H), 6.63 (s, 1H, 3-H), 4.75 (s, 2H, 5- $\mathrm{OCH}_{2}$ ), 4.07, 3.97 (2s, $\left.6 \mathrm{H}, 2 \mathrm{OCH}_{3}\right), 3.83\left(\mathrm{~s}, 6 \mathrm{H}, 2 \mathrm{OCH}_{3}\right){ }^{13} \mathrm{C} \mathrm{NMR}\left(101 \mathrm{MHz}, \mathrm{CDCl}_{3}\right)$ : $\delta 177.75,169.79,162.07,161.92,151.38,146.65,145.38,141.69$, 137.27, 127.07, 121.91, 113.72, 111.09, 105.04, 71.23, 61.21, 60.72, 60.36, 54.57. ESI-MS: $\mathrm{m} / \mathrm{z}$ 455[M+K] ${ }^{+}$. calc: 455.11 .

5-(O-Carboxymethyl)-3',4',6,7,8-pentamethoxyflavone (12) yellow solid; $76 \%$ yield; m.p. $212-214{ }^{\circ} \mathrm{C}$; ${ }^{1} \mathrm{H}$ NMR $\left(400 \mathrm{MHz}, \mathrm{CDCl}_{3}\right): \delta 7.53\left(\mathrm{~d}, J=8.4 \mathrm{~Hz}, 1 \mathrm{H}, 6^{\prime}-\mathrm{H}\right), 7.35(\mathrm{~s}, 1 \mathrm{H}$, 2'-H), 6.95 (d, J = 8.5 Hz, 1H, 5'-H), 6.66 (s, 1H, 3-H), 4.76 (s, $\left.2 \mathrm{H}, 5-\mathrm{OCH}_{2}\right), 4.07,3.97\left(2 \mathrm{~s}, 6 \mathrm{H}, 2 \mathrm{OCH}_{3}\right), 3.91\left(\mathrm{~s}, 6 \mathrm{H}, 2 \mathrm{OCH}_{3}\right)$, $3.83\left(\mathrm{~s}, \mathrm{H}, \mathrm{OCH}_{3}\right) ;{ }^{13} \mathrm{C} \mathrm{NMR}\left(101 \mathrm{MHz}, \mathrm{CDCl}_{3}\right): \delta 178.78,170.80$, 162.98, 152.67, 152.47, 149.48, 147.68, 146.44, 142.76, 138.24, 123.12, 120.20, 112.12, 111.36, 108.67, 106.29, 72.26, 62.16, 61.76, 61.41, 56.18, 56.03. ESI-MS: m/z 485[M+K]+. calc:485.12.

General procedure for synthesis of amino acid ester derivatives of polymethoxyflavonoids 13a, 13b, 14a and 14b

A mixture of 11 or 12 (0.48 mmol), EDCl (0.72 mmol), 4- $N, N$-dimethylaminopyridine (DMAP, $0.96 \mathrm{mmol}$ ) and glycine methyl ester hydrochloride or $L$-phenylalanine methyl ester hydrochloride $(0.58 \mathrm{mmol})$ were dissolved in $20 \mathrm{~mL}$ dichloromethane, and the reaction was carried out at room temperature. The progress of the reaction was followed by TLC. After the reaction was completed, the solvent was removed, and the residue was poured into $50 \mathrm{~mL}$ of $\mathrm{HCl}(1 \mathrm{~mol} / \mathrm{L})$, and extracted with $\mathrm{CH}_{2} \mathrm{Cl}_{2}(3 \times 20$ $\mathrm{mL})$. The organic phases were combined and dried over anhydrous $\mathrm{Na}_{2} \mathrm{SO}_{4}$. After filtration, the solvent was evaporated to give a crude material. Purification by silica gel column chromatography [ $V$ (petroleum ether): $V$ (ethyl acetate) $=2: 1]$ afforded compounds 13a, 13b, 14a and 14b.
5-(0-Acetylglycine methyl ester)-4',6,7,8-tetramethoxyflavone (13a) yellow solid; $90 \%$ yield; m.p.164$166{ }^{\circ} \mathrm{C}$; ${ }^{1} \mathrm{H}$ NMR (400 MHz, $\left.\mathrm{CDCl}_{3}\right): \delta 10.02$ (s, $1 \mathrm{H}, \mathrm{CONH}$ ), $7.81\left(\mathrm{~d}, J=8.2 \mathrm{~Hz}, 2 \mathrm{H}, 2^{\prime}-\mathrm{H}\right.$ and $\left.6^{\prime}-\mathrm{H}\right), 6.96(\mathrm{~d}, \mathrm{~J}=8.3 \mathrm{~Hz}$, $2 \mathrm{H}, 3^{\prime}-\mathrm{H}$ and $\left.5^{\prime}-\mathrm{H}\right), 6.56$ (s, $\left.1 \mathrm{H}, 3-\mathrm{H}\right), 4.74$ (s, 2H, 5- $\mathrm{OCH}_{2}$ ), $4.13\left(\mathrm{~d}, J=5.8 \mathrm{~Hz}, 2 \mathrm{H}, \mathrm{CH}_{2} \mathrm{CO}\right), 4.05,3.95,3.82,3.81$ (4s, $\left.12 \mathrm{H}, 4 \mathrm{OCH}_{3}\right), 3.68\left(\mathrm{~s}, 3 \mathrm{H}, \mathrm{CH}_{3}\right) .{ }^{13} \mathrm{C} \mathrm{NMR}\left(101 \mathrm{MHz}, \mathrm{CDCl}_{3}\right): \delta$ 178.12, 170.22, 170.07, 162.60, 161.88, 152.05, 147.90, 146.84, $142.29,137.79,127.85,123.37,114.64,112.93,106.54,73.65$, 62.15, 61.68, 61.45, 55.55, 52.15, 40.81.

5-(0-Acetylglycine methyl ester)-3',4',6,7,8-pentamethoxyflavone (13b) yellow solid; $87 \%$ yield; m.p.140$142{ }^{\circ} \mathrm{C}$; ${ }^{1} \mathrm{H}$ NMR (400 MHz, $\left.\mathrm{CDCl}_{3}\right): \delta 10.02(\mathrm{~s}, 1 \mathrm{H}, \mathrm{CONH})$, 7.48 (d, $\left.J=8.4 \mathrm{~Hz}, 1 \mathrm{H}, 6^{\prime}-\mathrm{H}\right), 7.31$ (s, 1H, 2'-H), 6.91 (d, $J=8.5$ $\mathrm{Hz}, 1 \mathrm{H}, 5$ '- $\mathrm{H}$ ), 6.55 (s, 1H, 3-H), 4.72 (s, 2H, 5- $\mathrm{OCH}_{2}$ ), 4.11 (d, $\left.J=5.7 \mathrm{~Hz}, 2 \mathrm{H}, \mathrm{CH}_{2} \mathrm{CO}\right), 4.04,3.94\left(2 \mathrm{~s}, 6 \mathrm{H}, 2 \mathrm{OCH}_{3}\right), 3.87(\mathrm{~s}$, $\left.6 \mathrm{H}, 2 \mathrm{OCH}_{3}\right), 3.80\left(\mathrm{~s}, 3 \mathrm{H}, \mathrm{OCH}_{3}\right), 3.67\left(\mathrm{~s}, 3 \mathrm{H}, \mathrm{CH}_{3}\right) .{ }^{13} \mathrm{C} \mathrm{NMR}$ $\left(101 \mathrm{MHz}, \mathrm{CDCl}_{3}\right): \delta 177.04,169.19,169.06,160.69,151.25$, $151.05,148.32,146.83,145.75,141.25,136.67,122.41,118.81$, $111.80,110.30,107.52,105.60,72.58,61.03,60.65,60.41$, 55.08, 54.92, 51.12, 39.76.

5-(0-Acetylphenylalanine methyl)-4',6,7,8-tetramethoxyflavone (14a) yellow solid; 87\% yield; m.p.104-106 ${ }^{\circ} \mathrm{C}$; ${ }^{1} \mathrm{H}$ NMR (400 MHz, $\left.\mathrm{CDCl}_{3}\right): \delta 9.94(\mathrm{~d}, J=7.8 \mathrm{~Hz}, 1 \mathrm{H}$, CONH), 7.68 (d, $J=8.6 \mathrm{~Hz}, 2 \mathrm{H}, 2^{\prime}-\mathrm{H}$ and 6'-H), 7.17-6.97 (m, $\left.5 \mathrm{H}, \mathrm{C}_{6} \mathrm{H}_{5}\right), 6.80(\mathrm{~d}, J=8.6 \mathrm{~Hz}, 2 \mathrm{H}, 3$ ' $-\mathrm{H}$ and 5'-H), 6.46 (s, $1 \mathrm{H}, 3-\mathrm{H}), 4.76-4.70(\mathrm{~m}, 1 \mathrm{H}, \mathrm{CH}), 4.56\left(\mathrm{~s}, 2 \mathrm{H}, 5-\mathrm{OCH}_{2}\right), 3.94$, 3.85, 3.67, $3.66\left(4 \mathrm{~s}, 12 \mathrm{H}, 4 \mathrm{OCH}_{3}\right), 3.54(\mathrm{~s}, 3 \mathrm{H}), 3.16(\mathrm{~d}, J=9.7$ $\left.\mathrm{Hz}, 2 \mathrm{H}, \mathrm{CH}_{2} \mathrm{Ar}\right) .{ }^{13} \mathrm{C}$ NMR $\left(101 \mathrm{MHz}, \mathrm{CDCl}_{3}\right): \delta 177.54,172.12$, 169.41, 162.44, 161.43, 151.75, 147.69, 146.60, 142.04, 137.66, $137.18,129.20,128.23,127.65,126.55,123.12,114.50,112.82$, 106.44, 73.50, 61.99, 61.52, 61.28, 55.42, 53.76, 52.05, 37.63.

5-(O-Acetylphenylalanine methyl)-3',4',6,7,8-pentamethoxyflavone (14b) yellow solid; 84\% yield; m.p.110$112{ }^{\circ} \mathrm{C} ; \mathrm{H} \mathrm{HMR}\left(400 \mathrm{MHz}, \mathrm{CDCl}_{3}\right): \delta 9.92(\mathrm{~d}, J=7.9 \mathrm{~Hz}, 1 \mathrm{H}$, CONH), 7.52 (d, $\left.J=8.4 \mathrm{~Hz}, 1 \mathrm{H}, 6^{\prime}-\mathrm{H}\right), 7.34$ (s, 1H, 2'-H), 7.22$7.06\left(\mathrm{~m}, 5 \mathrm{H}, \mathrm{C}_{6} \mathrm{H}_{5}\right), 6.93(\mathrm{~d}, J=8.5 \mathrm{~Hz}, 1 \mathrm{H}, 5$ '- $\mathrm{H}), 6.59$ (s, $1 \mathrm{H}$, 3-H), 4.83-4.77 (m, 1H, CH), 4.64 (s, $\left.2 \mathrm{H}, 5-\mathrm{OCH}_{2}\right), 4.03,3.95$, 3.91, 3.89, $3.76\left(5 \mathrm{~s}, 15 \mathrm{H}, 5 \mathrm{OCH}_{3}\right), 3.61\left(\mathrm{~s}, 3 \mathrm{H}, \mathrm{CH}_{3}\right), 3.21(\mathrm{~d}, \mathrm{~J}$ $\left.=16.2 \mathrm{~Hz}, 2 \mathrm{H}, \mathrm{CH}_{2} \mathrm{Ar}\right) .{ }^{13} \mathrm{C}$ NMR $\left(101 \mathrm{MHz}, \mathrm{CDCl}_{3}\right): \delta 176.76$, 171.21, 168.36, 160.46, 151.20, 150.95, 148.35, 146.81, 145.86, 141.19, 136.66, 136.14, 128.25, 127.26, 125.56, 122.58, 118.77, $111.96,110.29,107.54,105.81,72.56,61.03,60.64,60.37$, 55.10, 54.98, 52.69, 51.13, 36.81 .

\section{Synthesis of polymethylflavones amino acid derivatives $5 a, 5 b, 6 a$ and $6 b$}

The solid of 13 or $14(0.21 \mathrm{mmol})$ was dissolved in $10 \mathrm{~mL}$ methanol, in a $100 \mathrm{~mL}$ round bottom flask, and $4 \mathrm{~mL}$ of 
$\mathrm{NaOH}(1 \mathrm{~mol} / \mathrm{L})$ solution were added dropwise. The reaction was carried out at room temperature and the reaction progress was tracked by TLC. After the reaction was complete, the solvent of the reaction solution was removed and water was added followed by $\mathrm{HCl}(1 \mathrm{~mol} / \mathrm{L})$ to adjust the $\mathrm{pH}$ to 2-3, The mixture was then placed in a refrigerator and allowed to stand for filtration. The filter cake was dried and recrystallized from anhydrous $\mathrm{C}_{2} \mathrm{H}_{5} \mathrm{OH}$ to give a yellow solid.

5-(0-Acetylglycine)-4',6,7,8-tetramethoxyflavone (5a) yellow solid; 89\% yield; m.p. 180-182 ${ }^{\circ} \mathrm{C}$; ${ }^{1} \mathrm{H}$ NMR (400 MHz, DMSO- $\left.d_{6}\right): \delta 9.69(\mathrm{t}, J=5.6 \mathrm{~Hz}, 1 \mathrm{H}, \mathrm{CONH}), 7.94(\mathrm{~d}$, $J=8.5 \mathrm{~Hz}, 2 \mathrm{H}, 2^{\prime}-\mathrm{H}$ and 6'-H), 7.07 (d, $J=8.5 \mathrm{~Hz}, 2 \mathrm{H}, 3$ ' $-\mathrm{H}$ and 5'-H), $6.79(\mathrm{~s}, 1 \mathrm{H}, 3-\mathrm{H}), 4.62\left(\mathrm{~s}, 2 \mathrm{H}, 5-\mathrm{OCH}_{2}\right), 4.06$ (s, $\left.3 \mathrm{H}, \mathrm{OCH}_{3}\right), 3.98\left(\mathrm{~d}, J=8.6 \mathrm{~Hz}, 2 \mathrm{H}, \mathrm{CH}_{2} \mathrm{COOH}\right), 3.96,3.86$, $3.83\left(3 \mathrm{~s}, 9 \mathrm{H}, 3 \mathrm{CCH}_{3}\right) .{ }^{13} \mathrm{C} \mathrm{NMR}\left(101 \mathrm{MHz}, \mathrm{DMSO}-d_{6}\right): \delta$ $177.30,171.45,169.27,162.58,161.37,151.85,147.60,146.18$, 142.57, 137.89, 128.25, 123.12, 115.04, 112.95, 106.36, 73.53, 62.33, 61.86, 61.77, 55.92, 40.85; ESI-MS: m/z $473[\mathrm{M}]^{+}$. calc:473.13.

5-(0-Acetylglycine)-3',4',6,7,8-tetramethoxyflavone (5b) yellow solid; $85 \%$ yield; m.p.110-112 ${ }^{\circ} \mathrm{C}$; ${ }^{1} \mathrm{H}$ NMR $\left(400 \mathrm{MHz}, \mathrm{DMSO}-d_{6}\right): \delta 9.71(\mathrm{t}, J=5.7 \mathrm{~Hz}, 1 \mathrm{H}, \mathrm{CONH}), 7.63$ (d, $\left.J=8.5 \mathrm{~Hz}, 1 \mathrm{H}, 6{ }^{\prime}-\mathrm{H}\right), 7.51$ (s, 1H, 2'-H), 7.13 (d, $J=8.6 \mathrm{~Hz}$, $1 \mathrm{H}, 5$ '- H), 6.94 (s, 1H, 3-H), 4.63 (s, 2H, 5- $\mathrm{OCH}_{2}$ ), 4.07, 3.98 (2s, $\left.6 \mathrm{H}, 2 \mathrm{OCH}_{3}\right), 3.96\left(\mathrm{~d}, J=5.8 \mathrm{~Hz}, 2 \mathrm{H}, \mathrm{CH}_{2} \mathrm{COOH}\right), 3.87$, 3.86, $3.84\left(3 \mathrm{~s}, 9 \mathrm{H}, 3 \mathrm{CCH}_{3}\right) \cdot{ }^{13} \mathrm{C}$ NMR $\left(101 \mathrm{MHz}, \mathrm{DMSO}-d_{6}\right) \delta$ 177.41, 171.40, 169.28, 161.35, 152.41, 151.90, 149.45, 147.64, 146.22, 142.59, 137.84, 123.20, 119.95, 112.95, 112.24, 109.30, $106.62,73.55,62.32,61.90,61.78,56.15,56.09,40.81$. ESIMS:m/z $503[\mathrm{M}]^{+}$. calc:503.14.

5-(0-Acetylphenylalanine)-4',6,7,8-tetramethoxyflavone (6a) yellow solid; 82\% yield; m.p.106-108 oC; ${ }^{1} \mathrm{H}$ NMR (400 MHz, DMSO- $\left.d_{6}\right): \delta 9.74(\mathrm{~d}, J=8.0 \mathrm{~Hz}, 1 \mathrm{H}$, CONH), 8.04 (d, $J=8.4 \mathrm{~Hz}, 2 \mathrm{H}, 2^{\prime}-\mathrm{H}$ and $\left.6^{\prime}-\mathrm{H}\right), 7.35-7.16$ (m, 5H, $\mathrm{C}_{6} \mathrm{H}_{5}$ ), 7.13 (d, J = 8.5 Hz, 2H, 3'-H and 5'-H), 6.93 (s, $1 \mathrm{H}, 3-\mathrm{H}), 4.58$ (d, $\left.J=9.0 \mathrm{~Hz}, 2 \mathrm{H}, 5-\mathrm{OCH}_{2}\right), 4.07,3.99,3.86$, $3.80\left(4 \mathrm{~s}, 12 \mathrm{H}, 4 \mathrm{OCH}_{3}\right), 3.19$ (d, $\left.J=4.8 \mathrm{~Hz}, 2 \mathrm{H}, \mathrm{CH}_{2} \mathrm{Ar}\right) .{ }^{13} \mathrm{C}$ NMR (101 MHz, DMSO- $\left.d_{6}\right): \delta 177.48,173.19,168.85,162.67$, $161.48,151.94,147.65,146.29,142.42,138.11,137.85,129.52$, 128.65, 128.41, 126.89, 123.20, 115.15, 112.84, 106.53, 73.52, 62.39, 61.91, 61.71, 55.99, 53.90, 37.24. ESI-MS: m/z $563[\mathrm{M}]^{+}$., calc:563.18.

5-(0-Acetylphenylalanine)-3',4',6,7,8-pentamethoxyflavone (6b) yellow solid; 82\% yield; m.p.106-108 ${ }^{\circ} \mathrm{C}$; ${ }^{1} \mathrm{H}$ NMR (400 MHz, DMSO- $\left.d_{6}\right): \delta 9.74(\mathrm{~d}, J=8.0 \mathrm{~Hz}, 1 \mathrm{H}$, CONH), 8.04 (d, $J=8.4 \mathrm{~Hz}, 2 \mathrm{H}, 2^{\prime}-\mathrm{H}$ and 6'-H), 7.35-7.16 (m, $5 \mathrm{H}$. $\mathrm{C}_{6} \mathrm{H}_{5}$ ), 7.13 (d, $J=8.5 \mathrm{~Hz}, 2 \mathrm{H}, 3^{\prime}-\mathrm{H}$ and 5'-H), 6.93 (s, 1H, 3-H), 4.58 (d, $\left.J=9.0 \mathrm{~Hz}, 2 \mathrm{H}, 5-\mathrm{OCH}_{2}\right), 4.07,3.99,3.86,3.80$ $\left(4 \mathrm{~s}, 12 \mathrm{H}, 4 \mathrm{OCH}_{3}\right), 3.19$ (d, J = 4.8 Hz, $\left.2 \mathrm{H}, \mathrm{CH}_{2} \mathrm{Ar}\right) .{ }^{13} \mathrm{C} \mathrm{NMR}(101$ MHz, DMSO- $\left.d_{6}\right): \delta 177.48,173.19,168.85,162.67,161.48,151.94$, $147.65,146.29,142.42,138.11,137.85,129.52,128.65,128.41$,
126.89, 123.20, 115.15, 112.84, 106.53, 73.52, 62.39, 61.91, 61.71, 55.99, 53.90, 37.24. ESI-MS: m/z $593\left[\mathrm{M}^{+}\right.$. calc:593.19.

\section{Antiproliferative Activity}

The antiproliferative activities of synthetic compounds against four human cancer cell lines (Aspc-1, SUN5, HepG-2 and HCT116) were evaluated by CCK-8 assay in vitro using Staurosporine as the positive control drug. All the cells were cultured in an RPMI 1640 medium containing 10\% FBS, incubated at $37{ }^{\circ} \mathrm{C}$ in a $5 \% \mathrm{CO}_{2}$ humidified incubator to keep the cells growing in the exponential phase. Briefly, Aspc-1, SUN5, HepG-2 and HCT116 cells in a $100 \mu \mathrm{L}$ culture medium were plated into a 96-well plate at 4000-5000 cells per well, respectively, and subsequently cultured in the RPMI 1640 medium containing 10\% FBS, incubated at $37{ }^{\circ} \mathrm{C}$ for $24 \mathrm{~h}$ prior to drug exposure. The selected compounds were weighed and dissolved in DMSO and then diluted with medium to the needed concentrations. Cells were treated with the final concentrations of 100, 50, 25 , 12.5, 6.25 and $3.125 \mu \mathrm{mol} / \mathrm{L}$ of the tested compounds and incubated for $48 \mathrm{~h}$ and then $20 \mu \mathrm{L}$ of $0.5 \%$ MTT solution was added to each well simultaneously and incubated at $37^{\circ} \mathrm{C}$ for $4 \mathrm{~h}$. The formed formazan crystals were dissolved by adding $150 \mu \mathrm{L}$ of DMSO. The optical density at $570 \mathrm{~nm}$ was determined on a microtiter plate reader. According to the inhibition ratios, the $\mathrm{IC}_{50}$ value was obtained.

Conflict of interest: The authors confirm that this article content has no conflict of interest.

Acknowledgments: We thank the Hunan Provincial Natural Science Foundation of China (NO.2018JJ2034) for financial support.

\section{References}

[1] Miyata Y, Oshitari T, Okuyama Y, Shimada A, Takahashi H, Natsugari $\mathrm{H}$, et al. Polymethoxyflavones as agents that prevent formation of cataract: nobiletin congeners show potent growth inhibitory effects in human lens epithelial cells. Bioorg Med Chem Lett. 2013;23:183-7.

[2] Guy L, Alexandre M, Sylviane T, Geneviève A, Joëlle D, Thierry C. Semisynthesis of natural flavones inhibiting tubulin polymerization, from Hesperidin. J Nat Prod. 2010;73:702-6.

[3] Tetsuta O, Yuji O, Yoshiki M, Hiroshi K, Hideyo T. Hideaki, N. Nobiletin metabolites: synthesis and inhibitory activity against matrix metalloproteinase-9 production. Bioorg Med Chem Lett. 2011;21:4540-4.

[4] Li S, Pan MH, Lai CS, Lo CY, Dushenkov S, Ho CT. Isolation and syntheses of polymethoxy flavones and hydroxylated polymethoxyflavones as inhibitors of HL-60 cell lines. Bioorg Med Chem. 2007;15:3381-9. 
[5] Demetrio R, Benedetta M, Maria VR, Fabiana P, Giuseppe D. Recent discoveries of anticancer flavonoids. Eur J Med Chem. 2017;142:213-28.

[6] Marco B, Rosa T. Brigitte, D.; Monica, R. L.; Federica, M.; Francois, T. Francesco Menichini, In vitro biological evaluation of novel 7-O-dialkylaminoalkyl cytotoxic pectolinarigenin derivatives against a panel of human cancer cell lines. Bioorg Med Chem Lett. 2008;18:5431-4.

[7] Young HL, Hyoung JK, Ho Y, Seo YJ, Bong JK, Nam JK, et al. Synthesis of (2-amino)ethyl derivatives of quercetin 3-O-methyl ether and their antioxidant and neuroprotective effects. Bioorg Med Chem. 2015;23:4970-9.

[8] Lv XH, Liu H, Ren ZL, Wang W, Tang F, Cao HQ. Design, synthesis and biological evaluation of novel flavone Mannich base derivatives as potential antibacterial agents. Mol Divers. 2019;23:299-306.

[9] Masayuki N, Kaori T, Yuzo T, Yoshinori M, Mamoru K, Kunitomo W. Increased bioavailability of tricin-amino acid derivatives via a prodrug approach. J Med Chem. 2011;54:1529-36.

[10] Kim MK, Park KS, Yeo WS, Choo H, Chong Y. In vitro solubility, stability and permeability of novel quercetin-amino acid conjugates. Bioorg Med Chem. 2009;17:1164-71.
[11] Kim MK, Kim Y, Choo H. Quercetin-glutamic acid conjugate with a non-hydrolysable linker; a novel scaffold for multidrug resistance reversal agents through inhibition of p-glycoprotein. Bioorg Med Chem. 2017;25:1219-26.

[12] Nguyen VS, Li W, Li Y, Wang QA. Synthesis of citrus polymethoxyflavonoids and their antiproliferative activities on hela cells. Med Chem Res. 2017;26:1585-92.

[13] Cai SL, Kong YY, Xiao D, Chen Y, Wang QA. Primary aminomethyl derivatives of kaempferol: hydrogen bond-assisted synthesis, anticancer activity and spectral properties. Org Biomol Chem. 2018;16:1921-31.

[14] Nguyen VS, Shi L, Wang SC, Wang QA. Synthesis of Icaritin and $\beta$-anhydroicaritin Mannich base derivatives and their cytotoxic activities on three Human cancer cell lines. Anticancer Agents Med Chem. 2017;17:137-42.

[15] Wang GQ, Yan LL, Wang QA. Synthesis and antiproliferative activity of flavonoid triazolyl glycosides. Heterocycl Commun. 2018;24:119-24.

[16] Zheng JK, Fang X, Cao Y, Xiao H, He LL. Monitoring the chemical production of citrus-derived bioactive 5-demethylnobiletin using surface-enhanced raman spectroscopy. J Agric Food Chem. 2013;61:8079-83. 